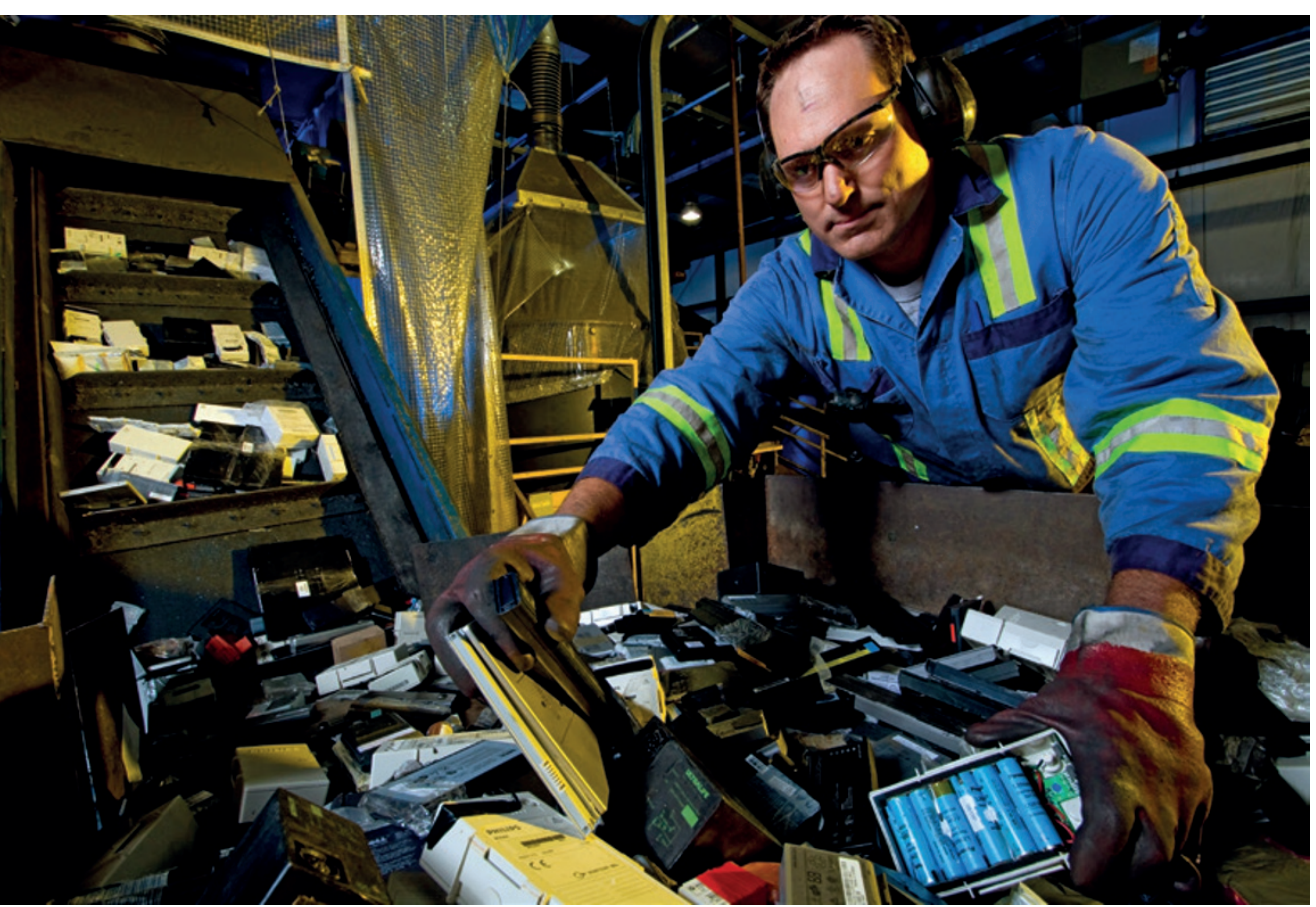

Processing of lithium-ion batteries for recycling at Retriev Technologies in Anaheim, California.

RECYCLING

\title{
Lazarus batteries
}

\author{
Battery recycling can be hard, energy intensive and \\ uneconomic. But soon, dead power cells could be more \\ easily resurrected.
}

\section{BY ERICA GIES}

S olar panels and wind turbines are becoming an increasingly common sight in many countries, and city dwellers are adjusting to the eerie hush of electric cars - nowhere more so than in Norway, where one-quarter of new vehicles sold in the first three months of 2015 were electric or hybrids. But these signs of progress towards a more-sustainable future rely on big batteries that are packed with chemicals and mined metals, and take large amounts of energy to manufacture.

Recycling can soften the environmental impact of batteries by reducing the energy required for their production, as well as the environmental harm caused by the disposal of hazardous battery materials and the mining of new ones. Sometimes, it can also provide an economic incentive, because valuable recovered materials can be sold on.

Unfortunately, most types of batteries are not being recycled, primarily because battery recycling is not required by law in most countries. Some US states have policies for certain battery types that encourage collection and recycling, but they do not make battery recycling compulsory. A European Union law mandates recycling, but it is being phased in over time. That leaves economics as a motivation, but in general, batteries do not contain enough precious metals to make recycling economically viable. In addition, the recycling processes available today reduce extracted metals back to their original form, meaning that multiple processes must be repeated to build a new battery from them.

But a promising technology could provide a much simpler and less destructive way to recycle batteries in the future. And better planning at the design stage could help.

\section{LEAD TAKES THE LEAD}

At present, one form of battery is already widely recycled. Lead-acid batteries (which are ubiquitous in petrol-fuelled cars) have about a $98 \%$ recycling rate in most developed countries, primarily because lead is toxic and its disposal is heavily regulated. Furthermore, most car batteries are replaced by professional mechanics, who are plugged into the batteryrecycling network.
Recycling lead-acid batteries also makes economic sense: it costs less than mining new lead, and because this heavy metal makes up about $65 \%$ of the battery's mass, it is easy to recover. The process saves money for the manufacturers and is lucrative for scrap dealers, says Joe Acker, who has worked in leadacid battery recycling for 25 years and is now president of Retriev Technologies, formerly Toxco, a battery-recycling company in Anaheim, California.

\section{LITHIUM-ION LAGS BEHIND}

But whereas lead-acid batteries are almost always recycled, it is much less common for the lithium-ion batteries in mobile phones, portable electronics and electric cars to be recovered. In the EU, just $5 \%$ of the lithiumion batteries sold in 2010 were recycled.

One reason for this low rate is that recycling lithium-ion batteries can be complicated. Lead-acid batteries have few materials and designs, says Linda Gaines, an analyst for the Center for Transportation Research at Argonne National Laboratory in Illinois, and breaking them apart to recover constituent parts is easy because the product is standardized across the market. Conversely, lithiumion batteries have various chemistries and shapes. The cathode could include cobalt, nickel, manganese, phosphorus and iron along with lithium, whereas the anode is typically carbon, and the organic electrolyte contains a lithium salt. Copper, aluminium and steel are also used as the substrate for the electrode materials and for the housing.

Much of the lithium-ion battery recycling so far has been motivated by the extraction of cobalt from the cathode, along with, to a lesser extent, nickel and copper. The value of these elements makes recycling economically attractive. In particular, cobalt is expensive and difficult to obtain; one of its primary sources is the conflict zone in the Democratic Republic of the Congo.

However, cobalt is gradually being phased out as researchers find cheaper cathode materials. So newer batteries, including "most of those now being built for vehicles, are less attractive for recycling by current methods", says Gaines.

Methods of recycling in commercial use today are based on metal refining. First and most widespread is pyrometallurgy, in which batteries are fed into a smelter and melted down to recover metals. In older lithium-ion batteries, cobalt might make up $18 \%$ of the battery. But the rest of the materials, including lithium and aluminium, end up in slag and are then buried or embedded in concrete.

The Brussels-based battery-recycling company Umicore uses pyrometallurgy to recover cobalt, nickel, copper and other metals from lithium-ion batteries and nickel-metal hydride batteries. However, profits from selling recovered metals are not a major driver of its 
recycling operation, says Maarten Quix, the firm's head of battery recycling. Rather, battery manufacturers pay the company to recycle their products. "Producers and collectors pay for the service in order to ensure that the credentials of 'green' products are solid, or to meet legislation targets," he says.

A second method, hydrometallurgy, is used by recyclers such as Retriev Technologies. In this process, cells are chopped up in water and separated into various product streams on the basis of what sinks, floats or hangs in solution. Chemicals are then added to the water, where they react with cathode components to make new compounds that are easier to separate.

\section{DIRECT RECOVERY}

But both pyrometallurgy and hydrometallurgy have limitations. Aside from their high energy and emissions footprint, many materials, including lithium and aluminium, end up in the waste stream after smelting, which means that more materials must be mined to build new batteries. "The model as it is now drains material away from batteries," says Steve Sloop, president of OnTo Technology, a research and development company in Bend, Oregon, that is working on recycling batteries.

Sloop developed a method called direct recovery. Rather than recovering basic elements, as with pyrometallurgy, or partially breaking down the molecular structure of compounds, as with hydrometallurgy, this method involves bathing the cathode in a soft chemical solution to rejuvenate it. The reactions are topotactic, meaning that structural elements of the cathode are retained, but its chemical composition is changed. In this way, cathode materials such as lithium that are not valuable enough to be recov-

\section{"Aluminium,} plastics, carbon and metal parts of the cell can all bereused."

ered by pyrometallurgy or hydrometallurgy can be reused in batteries. It is a low-temperature, low-energy, low-emissions process with very limited waste, he says.

"It's really cheap to do this," says Sloop. Most of the cost savings come from not having to rebuild the cathode again, and direct recovery uses less energy than pyro- and hydrometallurgical processes. It also produces fewer emissions and waste, saving money on compliance with air-pollution regulations and disposal fees.

The process is a closed-loop system, says Sloop: "Aluminium, plastics, carbon, metal parts of the cell can all be reused." He calculates that because of this thriftiness, direct recovery requires less than $2 \%$ of the energy required for new metal refining. Nor does it depend on large volumes; recyclers can add modular plants as the volume of material ramps up.

Gaines says that she sees great promise in direct recovery, which is also being developed by Retriev. "I don't see how any of the other
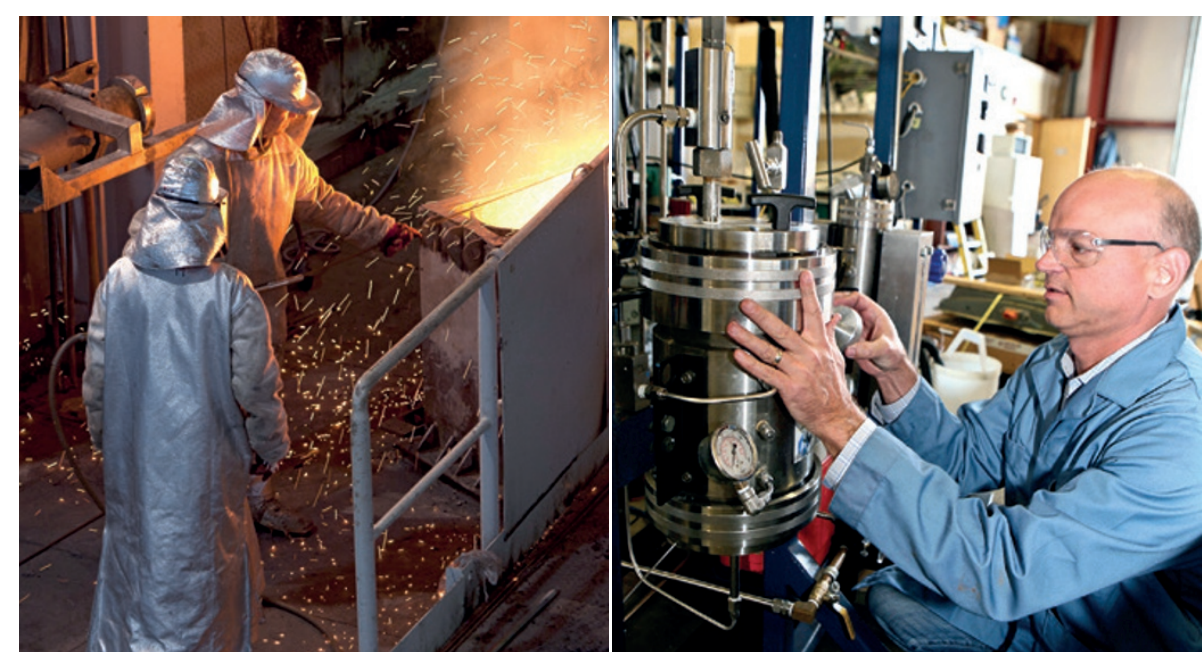

Pyrometallurgical processes convert used batteries into metal alloy (left); Steve Sloop has developed a method that produces fewer emissions and waste (right).

processes that have been developed so far can produce a valuable product from the cathodes that don't have valuable elements in them," says Gaines. With direct recovery, she says, "the value lies in retaining the materials in their battery-ready state".

Although direct recovery is not yet being used commercially, early tests are promising, says Sloop. "The performance levels are as high as with new materials." OnTo Technology is testing a car-grade battery built with rejuvenated material from a worn-out electricvehicle battery. "It's still cycling, 2,000 cycles later," he says.

\section{POLICY PUSH}

Until direct recovery has proved itself, topdown regulations can help to kick-start recycling programmes and drive innovation - as happened with lead-acid batteries. In the EU, a manufacturer is responsible for its product through its entire life cycle - especially collection, recycling and final disposal. The 2006 EU Battery Directive set a timeline for recycling progressively greater percentages of batteries and made the battery producers responsible for those efforts.

The programme is still in its early days - the directive's first target was $25 \%$ battery recycling by September 2012 and the next target is $45 \%$ by September 2016. The data so far are murky, says Gaines, so it is not yet clear how successful the directive has been in increasing recycling.

In the United States, there is no federal regulation for battery recycling, leaving a patchwork of state-level rules. Industry has made some effort to fill that gap. Since 1996, a voluntary programme called Call2Recycle, which is funded by electronics manufacturers, has recycled more than 38.5-million kilograms of small consumer batteries and mobile phones in the United States and Canada, but that is still just a tiny fraction of the total. Carl Smith, Call2Recycle's president, says that the organization recycles perhaps $2 \%$ of alkaline batteries and possibly $12 \%$ of lithium-ion ones. British Columbia, Quebec and Manitoba in Canada have mandatory recycling programme, and in these places, Call2Recycle collects about 25\% of what is sold, says Smith.

\section{PLANNINg AHEAD}

Prescient product design could help to increase recycling. Gaines has some ideas for strategies to facilitate recovery and reuse, such as using the minimum number of components, standardizing formats and materials, and avoiding toxic materials (such as cadmium, arsenic, mercury or halogens). She also recommends designs that more easily allow separation, such as nuts and bolts instead of welds.

Today's batteries are difficult and labourintensive to disassemble because not much thought goes into their end of life, says Acker. More than 130 energy-storage companies operate in California, but end-of-life concerns are widely ignored by innovators and the venture capitalists who fund them. Instead, they prioritize performance and cost, the better to grab market share. San José State University in California offers a battery-focused master's degree in electrical engineering that has courses on various kinds of electrochemistry, manufacturing and technology, but "end-oflife considerations do not enter into it", says Shahab Ardalan, the electrical engineer who oversees the master's programme.

That lack of foresight is unfortunate, says Gaines. "If you don't think about recycling early, you could develop some battery chemistry that's going to be completely intractable."

Nevertheless, she is hopeful about the future of battery recycling, particularly because direct recovery holds the promise of making it much more economic. Even if governments fail to wield policy sticks, economic carrots could finally deliver a greener energy future.

Erica Gies is a freelance science writer in Victoria, British Columbia. 